\title{
Virginia Woolf
}





\section{Virginia Woolf}

Ambivalent Activist

Clara Jones 
(C) Clara Jones, 2016

Edinburgh University Press Ltd

The Tun - Holyrood Road, 12(2f) Jackson's Entry,

Edinburgh EH8 8PJ

www.euppublishing.com

Typeset in 11/13 Adobe Sabon by IDSUK (DataConnection) Ltd, and printed and bound in Great Britain by CPI Group (UK) Ltd, Croydon CR0 4YY

A CIP record for this book is available from the British Library

ISBN 9781474401920 (hardback)

ISBN 9781474401937 (webready PDF)

ISBN 9781474410298 (epub)

The right of Clara Jones to be identified as the author of this work has been asserted in accordance with the Copyright, Designs and Patents Act 1988, and the Copyright and Related Rights Regulations 2003 (SI No. 2498). 